\title{
The Paradox of Scientific Universality
}

\author{
John Nwanegbo - Ben \\ Department of Philosophy of Science \& Technology, School of Management Technology Federal University of \\ Technology, Owerri.Nigeria.
}

\begin{abstract}
The question of the Universality of Science is of significance when we peruse it through an epistemological and social lens. Science has been seen to depend on universal laws that are valid and true anywhere in the world and has a high degree of probability. Some organizations are trying to developed a global scientific community on the basis of equity and non- discrimination. But there has been social and geographical divide buttressed by propaganda and this has nationalized science to the detriment of the up coming generation. This propaganda, does present a clear indication of the negation of the universality of science. The intent of this study is to help remedy this misnomer and to make us understand that there cannot be universality of science taking cognizance of the multi dimensional methods and the culture bound nature of science.
\end{abstract}

\section{Introduction}

The issue of the universality of science brings us to the question of the general perception of science. Science is generally regarded in three main ways. Firstly, science is seen as a body of knowledge, secondly, as a method of acquiring knowledge or studying and understanding the world. It has well known procedures for obtaining knowledge and thirdly, science could also be seen as an institution with millions of experts engaged in the development of human knowledge. It is knowledge arranged in an organized or orderly manner especially knowledge obtained by observation and experimentation.

The question now is, is scientific knowledge universal? Are its procedure universal and generally accepted by scientists? We may all be aware that science etymologically is derived from the Latin word scientia implying knowledge. However, we can make distinctions within this, such as the Natural Sciences, social sciences, cultural sciences and the formal sciences. Some thinkers see mathematicians as scientists, while others do not see mathematics as science because it does not require experimentation. In general mathematics is classed as formal science, while others like the natural and social sciences are classified as empirical sciences, ${ }^{1}$ the cultural sciences are history, religion and art, they all have an organized and systematic approach in their attempt to explicate phenomena both in the realm of the seen and unseen.

\section{When Is Scientific Knowledge Universal}

This question may lead us to the possibility of understanding what universality is. When we say that something is universal, it implies that, that thing or entity is consistent throughout the universe as opposed to relativism. In Logic, a proposition is said to have universality if it can be conceived as being true in all possible context without creating contradictions. Universals in metaphysics contrasts with particulars or individual cases. Platonic realism holds universals to be reference of general terms, which are abstract, nonphysical entities to which words like beauty, manhood, and whiteness refer.

The problem of universals is an ancient problem in metaphysics. Does the universal exist? In modern period, the reality of the universals was denied by George Berkeley and David Hume. They contended that only ideas of particular things exist. This is an empiricist position which is still held by empiricists today. When do we class scientific knowledge as universal? 2 × $2=4$ everywhere, both in New York and in a remote Oguta Town in the deltaic region of Imo state of Nigeria. Universals are concepts not just ideas in the mind. Bertrand Russell said that we recognize them in things that exhibit them and this means that they are real; though they are not physical. They are realities, though not tangible realities ${ }^{2}$ Mathematical exactitude can be comprehended anywhere in the world, yet it is devoid of observation and experimentation which is the basis of identifying what should be Natural sciences. Are all the procedures of science which includes the natural, social, cultural and formal sciences accepted by all scientists? If yes, what is peculiar or distinct between what is generally classed as western science; African science, etc. are the procedures and methodology different? If no, why western science and the propaganda?

Despite the methodology, the basic aim of science is explanation and hence, prediction of natural phenomena for the betterment of the living conditions of man. According to James Ladyman, "the realist place's emphasis on the power of scientific theories to explain the phenomena that they describe. Indeed, for many, 
explanation is the primary goal of the scientific enterprise ${ }^{3}$. The notion of the explanatory aim of science is as old as the period of ancient Egypt and Greek Philosophy and science. Since ancient times, it has always been in the nature of man to ask questions bordering on the ultimate nature of the universe and answers have been proffered. With progress made in science over the years, the mode of explanation in science has become more systematized, and this has enabled science to achieve a lot today in the realm of invention and discovery. The question now is did science become universal when it became more systematized or has it been a universal phenomenon? Is the universality of science predicated on the scientific methodology of a socio-cultural milieu? Is science and its development peculiar to the west or Europe? This brings us to the question, is science culture bound?

\section{Is Science Culture Bound}

It is a fact of life that each of us becomes culturally encapsulated during our socialization in childhood. We tend to accept the assumptions of our community culture, internalize the values, views of the universe, misconceptions and stereotypes. Most Europeans or western individuals have few opportunities to become free of cultural assumptions and perspectives that are monocultural, that devalue African and Asian cultures. Hegel held that Africans are intellectually inferior; Comte structured the growth of societies in three stages and placed his western society at the pinnacle of the developmental ladder. We may be postulating that these individuals were devoid of the history of science and technology taking cognizance of their time. A look at a contemporary philosopher of science shows that science could be culture bound if we view it from the position of a symbolic expression of a people. The words of Alex Rosenberg shows that the works of bias scholars as regards the claimed intellectual inferiority of races outside Europe or the western enclave have been imbibed by him. According to him "whether we like it or not, science seems to be the only universally welcome contribution of European civilization to all the rest of the world. It is arguably the only thing developed in Europe which every other society, culture, region, nation, population and ethnicity have learned about it has adopted from Europe...." ${ }^{4}$ He inclined that science originated in the west. Scholars like Rosenberg who write about the superiority of western science in contemporary era shows the level of indoctrination, bias and ignorance which has serious implications for the self-esteem for a very important part of the European populace.

The point being made here is that western bias scholars past and present, are not leaving any avenues untried in their effort to maintain the propaganda of Afriacanoid intellectual inferiority in ordered to avoid criticism from their own society that have accepted the concept of superiority. As a result of lack of historical and scientific foundations of these theories, Thomas Hodgkin said;

"It is no doubt flattering to our vanity to imagine that the people of Africa were" primitive" and "barbarous" before the penetration of the Europeans, and it is a theory that lacks historical foundation. The empire of Ghana flourished in what now is French West Africa during the dark ages of Western Europe. By the 15th century there was a university at Timbuktu. The Ashanti of Gold coast and the Yoruba of Nigeria possessed highly organized and complex civilizations long before their territories were brought under British political control. The thesis that Africa is what western European missionaries, traders, technicians and administrators have made it is comforting (to western Europeans). ${ }^{5}$ Africa, especially black Africa has an authentic scientific culture. An African and western scientists may attempted to investigate a phenomenon like Malaria. Each may start thus: the Western scientist would search for the causative agent e.g. the plasmodium, and the vector, the Anopheles mosquito. An African scientist would ask why that person in particular and not another was bitten by a disease carrying mosquito, in the hopes of preventing a recurrence of the event in future.

He goes on to say that science take chance for granted and rarely analyzes it, except perhaps to compile its likelihood of occurrence, but not why a change or accident has occurred.

Every particular scientific development may be culture bound and every culture has its own science which is a part of its total symbolic expression and so is inseparable from its architecture, art, sculpture and even religion. The question which concerns scientists of a particular culture, the choice of them, the framing of the questions and the methods of the thought are determined by the particular preoccupation of the people and the way in which the universe presented itself to their understanding. ${ }^{6}$

Western science have been based on regularities in nature, thus they select as its subject matter those that are regular and then finds it can predict their behaviour. These regularities however should not be the basis for concluding that irregular and probably irrational phenomena are not important. Imagine an experience situation observed by a scholar Olufemi Taiwo in one of his lectures in Chicago during a discussion concerning African philosophy in a third year philosophy of law class couple of years back. The students were puzzled to hear of African philosophy, such that one of the students stated that he had just heard of African philosophy for the first time in his life. Taiwo adds that he had to teach in a Jesuit university, "a significant order in the catholic church. Meanwhile, Africa is one of the few areas of the world where the Catholic Church is enjoying its most spectacular growth especially in terms of recruitment to the ministry. The student, who is probably catholic, had absolutely no clue about African contributions to global culture, including the fact that the future of the Church 
may depend upon African priests". ${ }^{7}$ We can see that culture appears to direct the thought pattern of people. If it is true that "The ghost of Hegel dominates the hallways, institutions, syllabi, instructional practices, and Journals of Euro-American philosophy. ${ }^{8}$ Then science is culture bound because it has been nationalized. If thus, what is universal about science? Is it applicability and validity of its method or the knowledge it provides that is universally sheered?

We may say that science transcends locality or culture, but it appears to bear the imprint of locality. In today's world the scientific and technological isolation of most humanity is clearly not acceptable. The culture bound perception of science is seen is Sam, Tunde, Bajah's definition of African science as a "systematic, complex and exclusive traditional process (commonly noticed in a number of African cultures), in which an attempt is made to describe, understand, predict and control nature" ${ }^{9}$. An African scientist considers the whole of a problem and does not believe it possible to isolate and control variables in all situations. African science accepts paradoxes and works with them. Every culture works with what is peculiar with them. Maduabuchi Dukor made this clear when he posits that "The traditions of Kant, Hegel, schelling, Marx etc. are forms of rational enquires into particular socio-political formation of their respective cultures". ${ }^{10}$ What Dukor is inferring here is that knowledge of various dimensions are culture bound.

The universality of science in its strict objective is about developing a truly global scientific community on the basis of equality and non-discrimination. It ensures that science is valued and trusted round the world independent of political, social or geographical divide. It tries to in-cooperate and take into consideration the conduct of science, education and general accesses to data and information and the relationship between science and society. However commented Loucas .G. Christopharou "Without proper access to scientific literature and technical information and without adequate means and materials needed for their indigenous sciences and techolongy, developing nations will continue to remind us of the limits of the universality of science ${ }^{11}$.

\section{The Illegitimacy Of Nationalizing Science And The Paradox Of Universality.}

Why western science, African science, etc? These distractions are products of propaganda that negates the concept of universality of science. The pivot of the problems lies in history. The fact that "whatever aspects of culture (including philosophy) impressed itself as of real value was though to be barrowed from another culture" 12 .Hegel referred to the North Africans noted for their richness in civilization as "European Africa". Hume in the first edition of the Treatise on Human nature stated that" there has not been any invention, any sign of civilization among the blacks" ${ }^{13}$ And in Hegel's Philosophy of History he dropped a bomb "In Negro life, the characteristics point is the fact that conscience has not yet attained to the realization of any substantial objective existences.... cannibalism is looked upon as quite customary and proper.... ${ }^{14}$ With this infinitesimal expression among the avalanche of others, what do we expect from the scholars who look up to him in high esteem. The tradition as regards such propaganda as the superiority of a nationalized science (western science) would definitely stultify the idea of a universal science.

What should be well noted again is that the world is a hybrid of complexities and as such the perception of those advocating for the superior of a particular or nationalized science may be totally misleading. Hence the task of nationalizing science is a misnomer. According to G. Frege in his book, Logical investigation "to discover truth is the task of all sciences, it falls to Logic to discern the laws of truth ${ }^{15}$. This means that it falls on other forms of science to discern theirs. The generally perceived procedures of science which is now seen as the scientific method, is not the only way to the truth.

The search for truth in science imposes on the Scientists a moral conduct. Science changes and so its values and scientific behavior. It would from my perception be difficult to change the moral value of a religious extremist involved in science. With such personality discoveries may be kept away or localized, thus values can stand against the universality of science.

\section{Conclusion}

The inference one is drawing from this is that the issue of the universality of science is a paradox because all these nationalized or culture bound sciences differ in their search for truth in relation to methodology. How would there be universality when there exist secrecy, pride of superiorly over others. In additions beyond what the empirical scientist can probe is the science of the paranormal. The paranormal scientists follow certain methods or procedures, not always predicated on observable empirical tools like that of the empirical scientists, "medicine men" or magicians. They may arrived at observable results without the use of empirical tools of investigation ${ }^{16}$.To dismiss these "non - physical" aspects of human reality because they do not conform to empirical evidence by the "method of science" limits the universality of science. Thus, science is not universal and to talk of the universality of science is paradoxical. 


\section{References}

[1]. Mario August .O. Bunge, Philosophy of Science: From problem to theory Translations Publishers. 1998. P. 24.

[2]. Bertrand Russell Problems of Philosophy Oxford. OUP. 1983. PP.52-57.

[3]. James Ladyman "Understanding Philosophy of Science London. Rutledge: 2002.P.196.

[4]. Alex Rosenbars Philosophy of Science: A contemporary introduction. New-York: Routledge. 2005. PP.13-14.

[5]. T. Hodgkin "National Movements in West African "in The Highway. 1952. PP. $169-170$.

[6]. Nwankwo Ezeabasili. African science: Myth or Reality New York: Vantage Press. 1977. P.87.

[7]. Olufemi Taiwo. Exorcising Hegel's Ghost: African's Challenge to philosophy. African Studies Quarterly. The Online Journal for African studies. www.africa.ufl.edu/asq/vi_14htm Retrieved 9/9/2012. Or see African Studies Quarterly Vol. 1, Issue.4. University of Florida. 1998. pp.3-16.

[8]. Ibid.

[9]. Bajah, Sam, Tunde African science: Facts or Fiction a multidimensional Approach with bias towards science education. Intellectual life committee Monograph 1, California State university. 1980. P.6.

[10]. Maduabuchi Dukor. Theistic Pan psychic Communicative Rationality Open Journal of Philosophy. 2011. Vol. 1 No .2, . PP $76-83$.

[11]. Loucas .C. Christophorou. The Universality of Science: Limits and needs. Being lecture at the international council for Science (ICSU) European members annual meeting. 29- 30. Sept 2009.podgorica,Montenegro.

[12]. www.academyofathens.gr.1.universality of scientists Retrieved 2/2/2013.

[13]. G. Ehusani, An Afro- Christian Vision, Ozovehe. Towards A more Humanized World. New York: University. Press. 1991. P.78.

[14]. David Hume. Treatise on Human Nature $1^{\text {st }}$ Edition. Preface Cited in Ibid. P.81.

[15]. G. Hegel. Philosophy of History. New York: Willey Books

[16]. G. Frege. Logical Investigation Britain: Basil Blackwell.1977.p.1

[17]. John Nwanegbo- Ben. A philosophical Investigation of www.naudigitalibrary.wordpress.com/tag/john-nwanegbo-ben.

Co. 1944.P.91

the paranormal and the future of experimental science. 